\title{
Some provocative thoughts on damage and repair of DNA
}

\author{
Celina Janion* \\ Institute of Biochemistry and Biophysics, Polish Academy of Sciences, Pawinskiego 5a, 02-106 Warszawa, Poland
}

The instability of nucleic acid bases, responsible for hereditary information storage is amazing. Is there a system in this madness? All the nitrogen bases may undergo different kinds of rapid, spontaneous, or induced modification. They may form adducts and photoproducts, may be deaminated, methylated, and oxidized, or may be lost spontaneously or in the course of enzymatic processes. The list of potentially mutagenic lesions in DNA is long (some of them are given in parentheses) and includes products of deaminations (hypoxanthine, uracil, 5-methyluracil (thymine)); of methylation (3-methyladenine, O-6-methylguanine); of oxidation (8-oxoguanine, thymine glycol, 5-hydroxycytosine, 5-hydroxyuracil, 5-formyluracil), and apurinic/apyrimidinic (AP) sites. The frequency of base oxidation much outweighs the remaining modifications. The most susceptible base to oxidation damage (and to depurination), both in nucleotide pools as well as in DNA, is guanine, with formation of the highly mutagenic base, 8-oxoguanine. It has been calculated that in a single cell per day as much as $\sim 100000$ modification events occur $[1,2]$. Modified bases may be restored by (1) direct reversal of the modifying reaction (e.g., by action of photolyases that reverse pyrimidine dimers and 6-4 pyrimidine photoproducts to native pyrimidines [3-5] or by action of O-6-methylguanine DNA methyltransferase, a suicide enzyme that removes methyl (or alkyl) from O-6-alkylguanine residues in DNA and accepts it on its own Cys321 residue [6] and (2) by processes of base excision- or nucleotide excision-repair (BER or NER) [7-10]. About six distinct DNA-glycosylases, at least, are found in bacteria and their homologues have been detected in mammalian cells. There is a common mechanism for BER which includes: (i) attachment of the enzyme to the damaged site, (ii) flipping out a modified base (or AP-sites) of the double-stranded structure, excising a base, (iii) interruption of the phosphodeoxyribose chain to form a $3^{\prime} \mathrm{OH}$ end, (iv) filling the gap with matching nucleotides, and ( $\mathrm{v}$ ) sealing to restore the continuity of the DNA. BER begins with removal of a modified base, and then 1 to 10 nucleotides are undergoing exchange. In NER, a fragment of 12-13 nucleotides or 24-32 nucleotides is excised in bacteria and mammalian cells, respectively [11]. The NER system excises a broad spectrum of structurally unrelated DNA lesions, pyrimidine dimers, and 6-4 photoprod- ucts, but also excises 8-oxoguanine, and thymine glycols from DNA [9]. Yet another, mismatch repair system, acts on native (or modified) mismatched bases shortly after replication, when distinction between the new synthesized and the old strand of DNA is possible $[12,13]$. In the course of the repair of a single mismatch by mismatch repair system as many as 1000-2000 nucleotides may be excised [14]. When all kinds of modifications and repair are considered, it can be calculated that in a single cell, in the course of DNA repair per day as many as $2 \times 10^{6}$ base pairs are exchanged $\left(\sim 10^{6}\right.$ arise from base modification, and $10^{6}$ from mismatch repair). This covers a large fraction of genomic DNA. Therefore, the question may be posed of whether the huge number of enzymes for DNA repair, arose in a long process of evolution as a defense system against different modifications, or if they are part of normal DNA metabolism to keep molecules in a continuous dynamic state? Apparently, nature prefers modification and repair to firm stability. Therefore, is modification of the bases a method for quick response to situations in the environment and thus a source of evolution? A natural bases in DNA are necessary before it is replicated, the cell cycle apparatus and checkpoint proteins control DNA damage and halt cell division until repair of DNA is complete.

\section{ACKNOWLEDGEMENTS}

I am very grateful to Professor Ronald Hancock for the critical reading and English corrections.

\section{REFERENCES}

[1] Smith KC. Spontaneous mutagenesis: experimental, genetic and other factors. Mutat Res. 1992;277:139-162.

[2] Jiricny J. Replication errors: cha(le)nging the genome. EMBO J. 1998;22:6427-6436.

[3] Sancar A. Structure and function of DNA photolyase. Biochemistry. 1994;33:2-9.

[4] Sancar BG. DNA photolyases: physical properties, action mechanism, and roles in dark repair. Mutat Res. 1990;236:147-160.

[5] Toddo T. Functional diversity of the DNA pho- 
tolyase/blue lights receptor family. Mutat Res. 1999; 434:89-97.

[6] Friedberg EC, Walker GC, Siede W. DNA repair and mutagenesis. Washington DC: ASM press; 1996:91-133.

[7] Krokan HE, Standahl R, Slupphaug G. DNA glycosylases in the base excision repair of DNA. Biochem J. 1997;325:1-16.

[8] Wyatt MD, Allan JM, Lau AY, Ellenberger TE, Samson LD. 3-methyladenine DNA glycosylases: structure, function, and biological importance. Bioessays. 1999;21:668676.

[9] Petit C, Sancar A. Nucleotide excision repair: from $E$. coli to man. Biochimie. 1999;81:15-25.

[10] Mol CD, Parikh SS, Putnam CD, Lo TP, Tainer JA. DNA repair mechanisms for the recognition and removal of damaged DNA bases. Annu Rev Biophys Biomol Struct. 1999;28:101-128.
[11] Le Page F, Gentil A, Sarasin A. Repair and mutagenesis survey of 8-hydroxyguanine in bacteria and human cells. Biochimie. 1999;81:147-153.

[12] Lahue RS, Au KG, Modrich P. DNA mismatch correction in a defined system. Science. 1989;245:16-184.

[13] Jiricny J. Eukaryotic mismatch repair: an update. Mutat Res. 1998;409:107-121.

[14] Wagner R, Meselson M. Repair tracts in mismatched DNA heteroduplexes. Proc Natl Acad Sci USA. 1976;73:4135-4139.

${ }^{*}$ E-mail: ce1ina@ibb.waw.p1

Fax: +48 39121623 

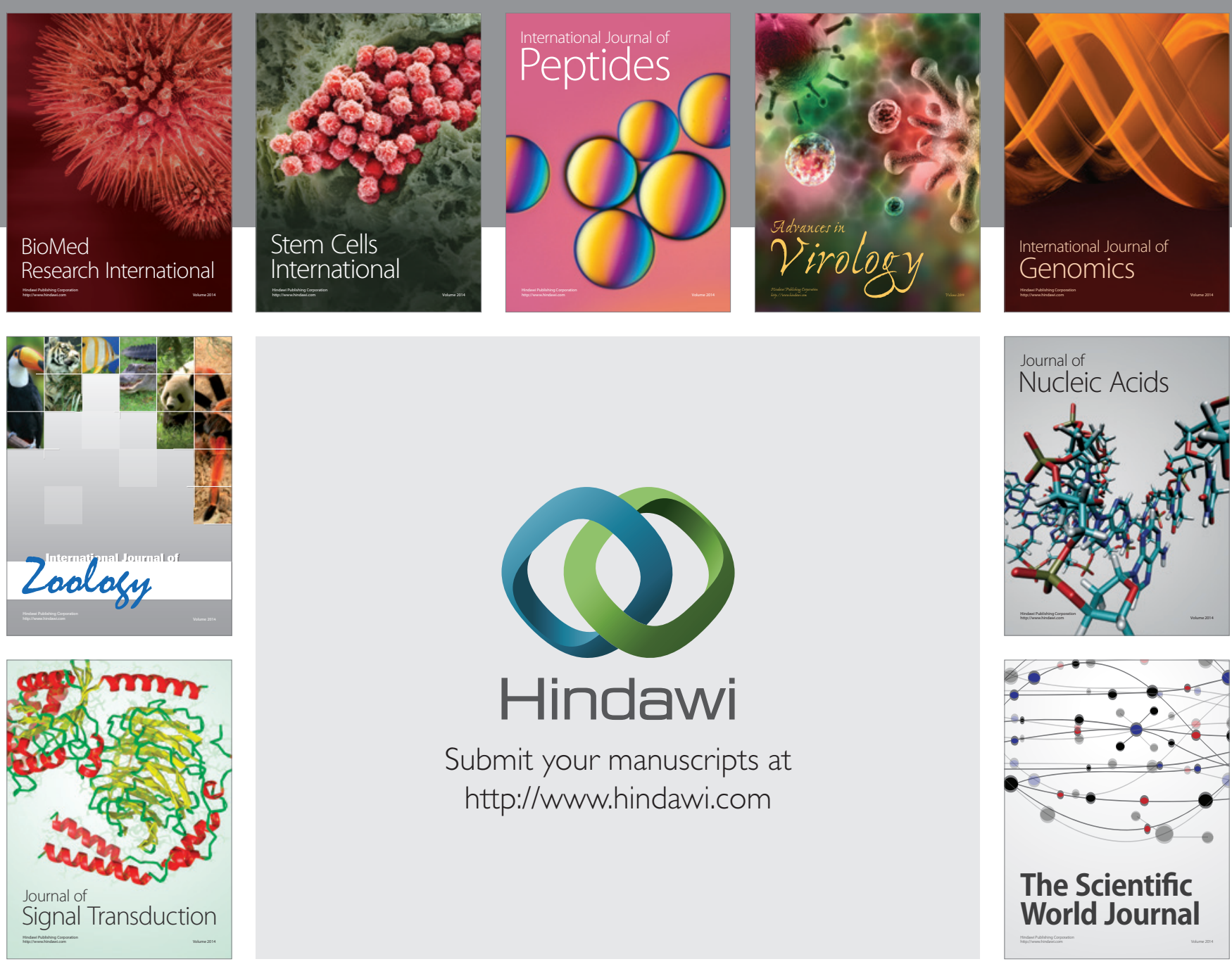

Submit your manuscripts at

http://www.hindawi.com
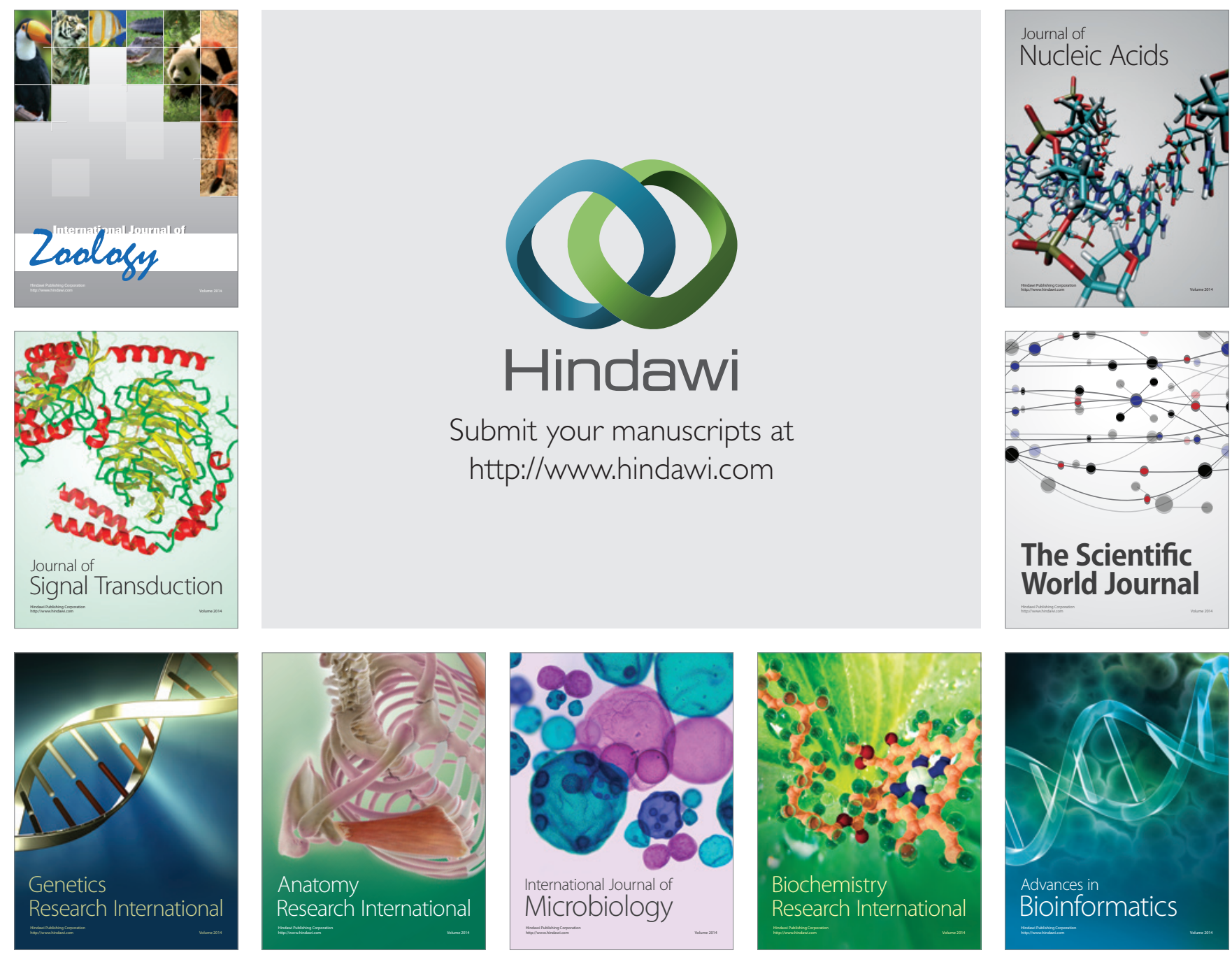

The Scientific World Journal
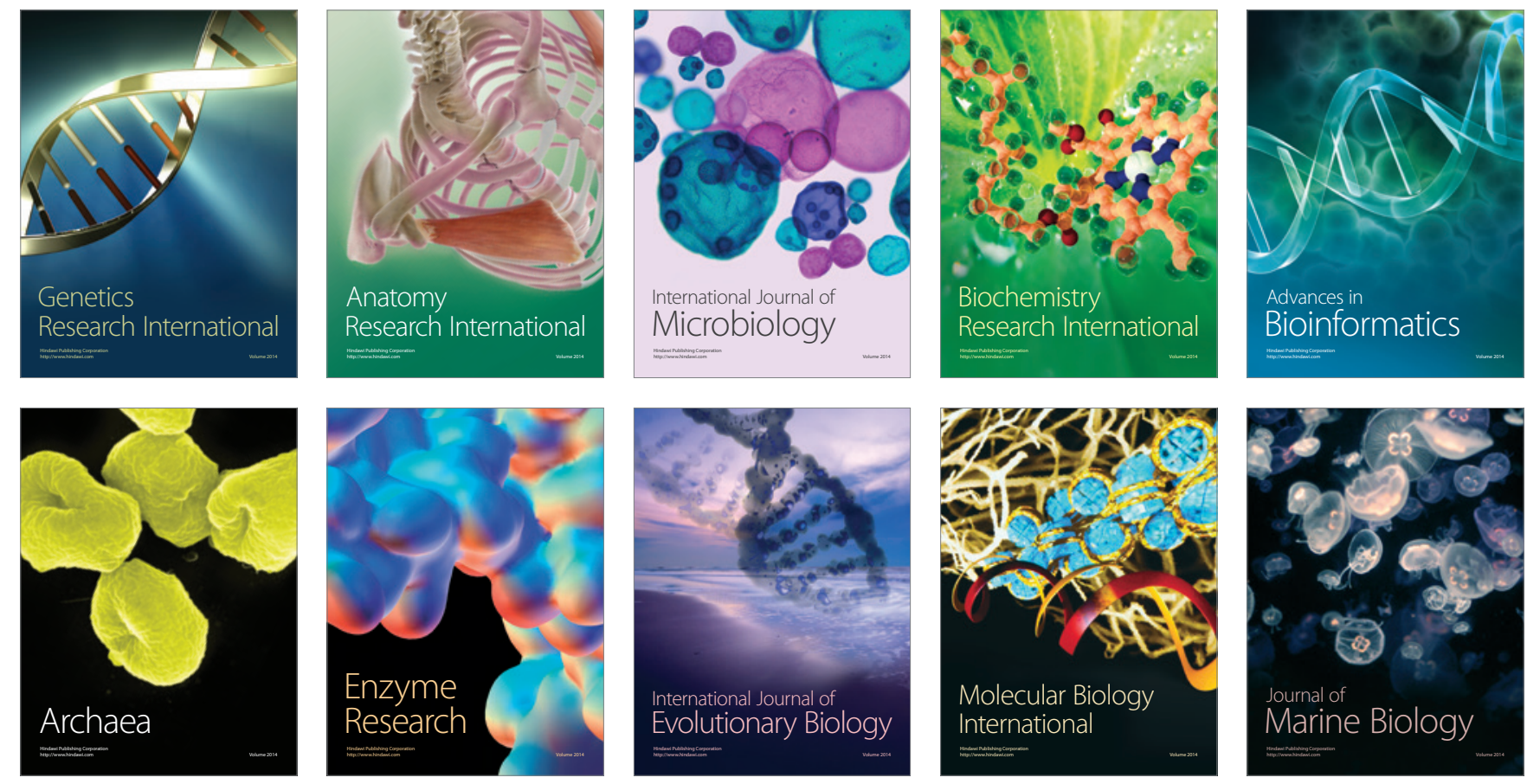